\title{
Shallow bias in Mediterranean paleomagnetic directions caused by inclination error
}

\author{
Wout Krijgsman ${ }^{\mathrm{a}, \mathrm{b}}$, Lisa Tauxe ${ }^{\mathrm{b}, *}$ \\ a Paleomagnetic laboratory "Fort Hoofddijk", Budapestlaan 17, 3584 CD, Utrecht, The Netherlands \\ ${ }^{\mathrm{b}}$ Scripps Institution of Oceanography, University of California, San Diego, 9500 Gilman Drive, La Jolla, CA 92093-0220, USA
}

Received 8 October 2003; received in revised form 25 February 2004; accepted 3 March 2004

\begin{abstract}
A variety of paleomagnetic data from the Mediterranean region show a strong bias toward shallow inclinations. This pattern of shallow inclinations has been interpreted to be the result of (1) major northward terrane displacement, (2) large nondipole components in the Earth's magnetic field, and (3) systematic inclination flattening of the paleomagnetic directions. Here, we use the observation that, in addition to the well-known variation of magnetic inclination with latitude, the $\mathrm{N}-\mathrm{S}$ elongation of directional dispersion also varies, being most elongate at the equator and nearly symmetric at the poles. Assuming that inclination shallowing follows the relationship long known from experiment, we invert the inclinations using a range of "flattening factors" to find the elongation/inclination pair consistent with a statistical model for the paleosecular variation. We apply the so-called "elongation/inclination" method to the extensive paleomagnetic data sets from the Miocene sediments of the Calatayud basin (Spain) and the island of Crete (Greece). After correction, the Spanish data are in good agreement with the expected middle Miocene latitude of the region. The data from Crete suggest that it occupied a position in the late Miocene about $275 \mathrm{~km}$ north of the predicted location. This is in agreement with the geological and geodynamical models for the east Mediterranean region, which indicate that slab rollback processes in combination with Anatolian push generated southward migration of Crete. The 7.5 million year average displacement rate of Crete estimated by the $E / I$ method is $37 \mathrm{~mm} / \mathrm{yr}$ to the south, which closely coincides with present-day rates based on global positioning system (GPS) and model measurements. We also show that inappropriate tilt corrections lead to a shallow inclination bias as well, explaining that observed in studies of lava flows of the region. We conclude that the east Mediterranean inclination anomaly is caused by sedimentary inclination error and not by a persistent octupolar contribution to the geomagnetic field, or northward transport.
\end{abstract}

(C) 2004 Elsevier B.V. All rights reserved.

Keywords: geocentric axial dipole (GAD) hypothesis; inclination error; paleosecular variation model; elongation/inclination method; GPS

\section{Introduction}

Paleomagnetic data can be very useful for geodynamic reconstructions because they allow a quantita-

\footnotetext{
* Corresponding author. Tel.: +1-858-534-6084; fax: +1-858534-0784.

E-mail address: 1tauxe@ucsd.edu (L. Tauxe).
}

tive estimation of both rotations around vertical axes and latitudinal tectonic transport. The fundamental concept in the use of paleomagnetism for plate tectonic studies is that the Earth's magnetic field is, on the average, a geocentric axial dipole (GAD). The GAD hypothesis implies that a paleomagnetic pole indicates the position of the rotational axis with respect to the continent from which the paleomagnetic data were 
acquired. It allows us to calculate the geographic (paleo)latitude of any site from the measured inclination according to the equation: $\tan I=2 \tan \lambda$, where $I$ is the magnetic field inclination and $\lambda$ is the geographic latitude at the point of measuring.

A variety of paleomagnetic data from different regions of the Earth show a strong bias toward shallow inclinations, sometimes interpreted to be inconsistent with a GAD model for the ancient timeaveraged geomagnetic field (e.g., [1]). These anomalously shallow inclinations have been explained by northward movement of terranes or microplates, especially in tectonically active regions like Central Asia (e.g., [2]), the North American cordillera (e.g., [3-6]), and the Mediterranean (e.g., [7-9]). Geolog- ical evidence supporting such large translations is generally lacking (e.g., $[10,11])$ and other explanations have been proposed, including the existence of a persistent nondipole field (e.g., $[12,13])$ and inclination errors in the paleomagnetic data (e.g., [14-17]).

In this paper, we will apply a different approach to investigate the shallow bias in the Mediterranean paleomagnetic directions. This approach is based on the statistical field model of Tauxe and Kent [18] referred to as TK03.GAD, and their elongation/inclination $(E / I)$ method which can be used to correct for inclination errors in sediments, given sufficient observations $(N>\sim 100)$. We have selected the Miocene sediments of the Calatayud basin (Spain) and the island of Crete (Greece) because extensive data sets (between

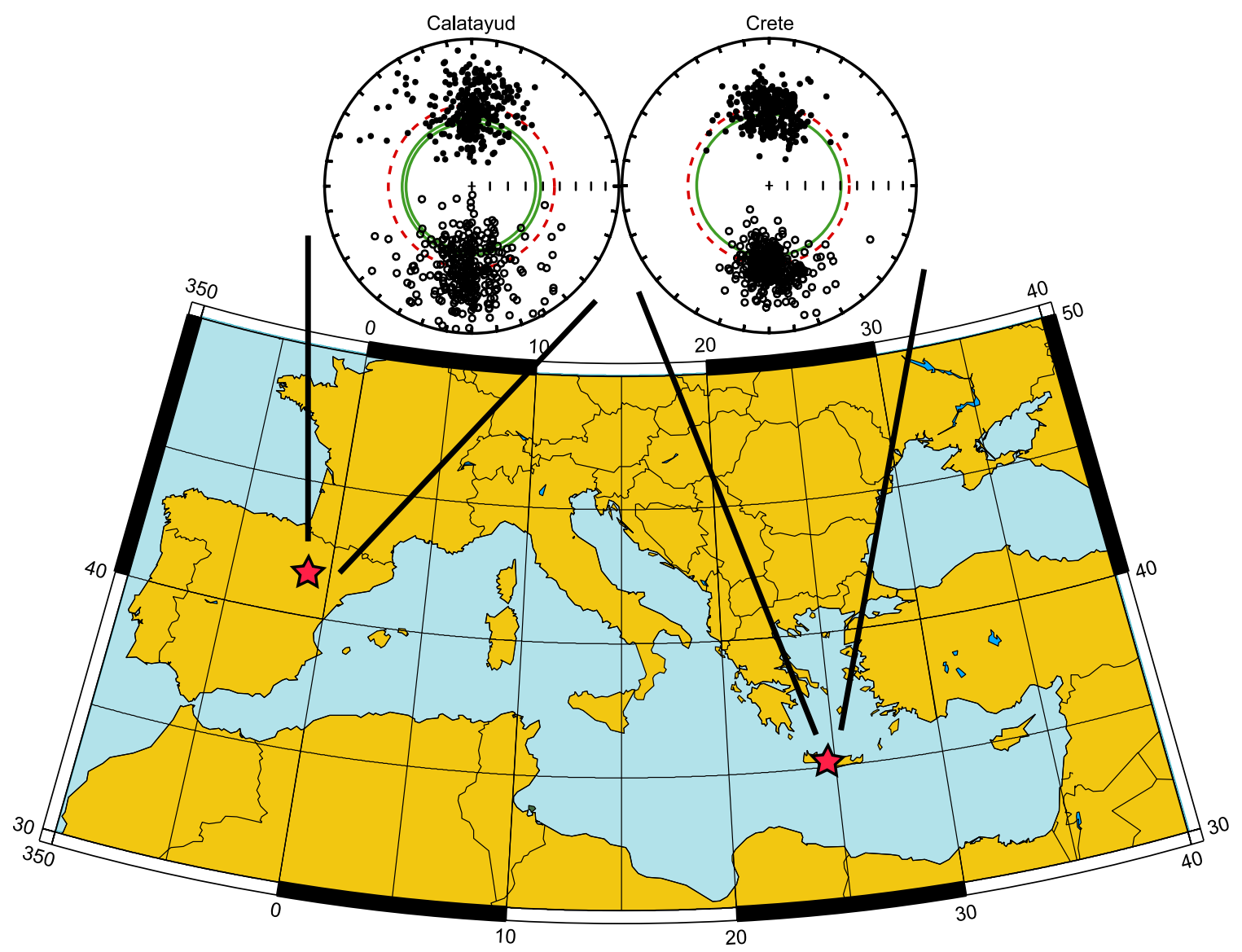

Fig. 1. Map of the Mediterranean region showing the location of the Calatayud basin in northeast Spain and the island of Crete in the eastern Mediterranean. Equal area projections are (left) middle to late Miocene continental deposits from [35,36] and (right) late Miocene marine marls from [41-43]. Solid (open) symbols are lower (upper) hemisphere projections. Mean inclinations of the raw paleomagnetic data are indicated by dashed line. Expected inclinations according to the BC02 reconstruction are indicated by a solid line. 
600 and 700 sites) exist for these two regions, which show a clear shallow bias in the paleomagnetic directions (Fig. 1). In addition, both regions have experienced a different geodynamic evolution after deposition of the sediments. Spain has occupied a "locked" position between Europe and Africa and has not shown any differential translation with respect to these continents since the early Miocene (e.g., [19]), while Crete has undergone significant southward translation according to most geological models (e.g., [2022]) and geodetic analyses (e.g., [23]). By applying the E/I method to the directional data of Spain and Crete, we will show that the anomalously shallow inclinations in the Mediterranean can be explained by sedimentary inclination error.

\section{The elongation/inclination method}

Fortunately, there is much more to a GAD field than the angle of inclination. Secular variation contributes scatter to both the directions and intensities of paleomagnetic vectors and the distribution of these vectors can be modelled using statistical geomagnetic field models of the type pioneered by Constable and Parker [24]. Tauxe and Kent [18] recently updated the so-called "Giant Gaussian Process" (GGP) statistical field model; their model, TK03.GAD fits the available data for the last 5 million years quite well and can be used to predict distributions of paleomagnetic field vectors as a function of paleolatitude (assuming of course that the geomagnetic field had the same statistical properties in the past as it had for the last five million years). We show representative realizations of TK03.GAD in Fig. $2 \mathrm{a}-\mathrm{c}$ at $0,30^{\circ}$ and $60^{\circ} \mathrm{N}$, respectively. The directions are plotted with the center of the diagram being the expected GAD field direction $\left(D^{\prime}, I^{\prime}\right.$ of [25]). As has been noted before (e.g., [2629]), the shape of the directions is not circular but elongate and the elongation is a function of latitude. This is an unavoidable consequence of a GGP-GAD field. Tauxe and Kent [18] quantify the degree of elongation using the parameter $E$ of [30] which is the
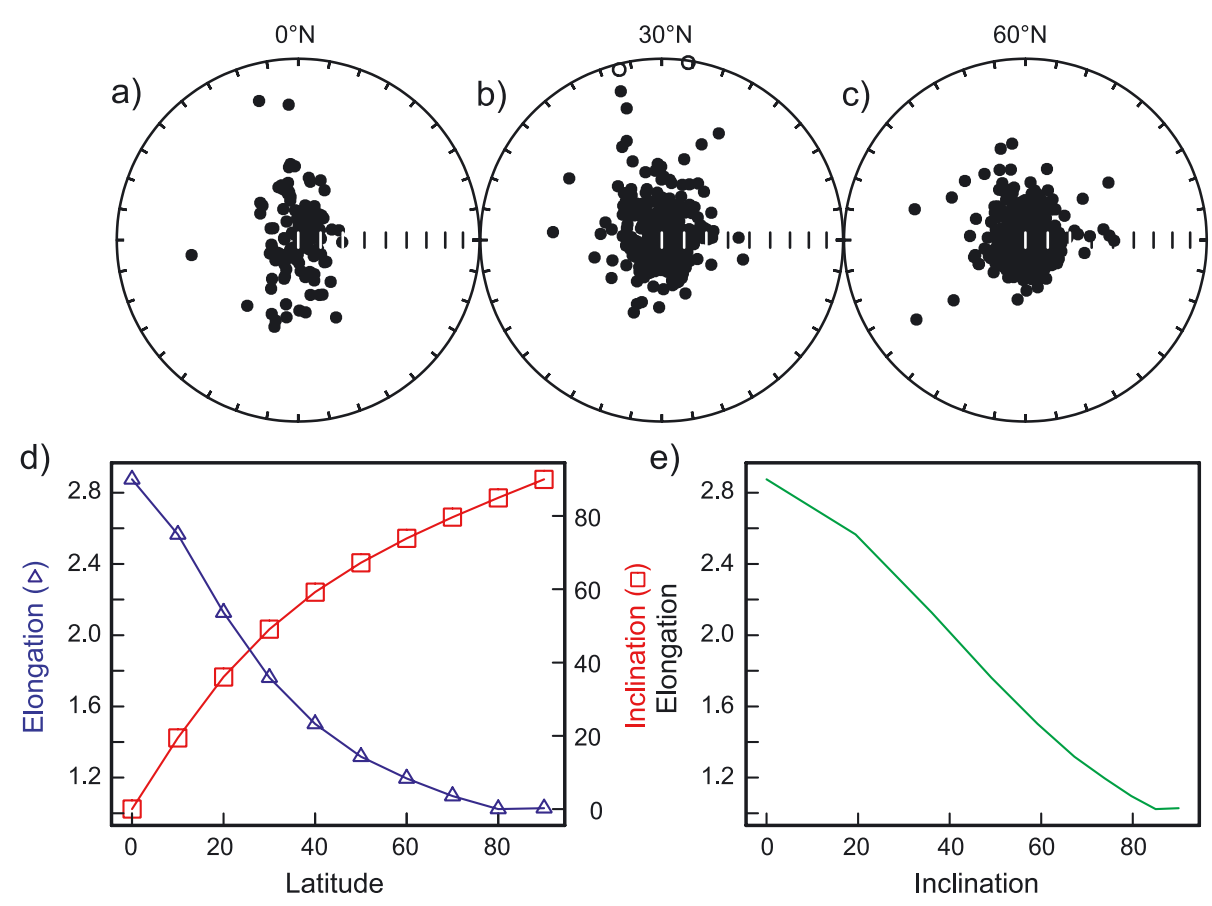

Fig. 2. Distributions of geomagnetic field directions drawn from the statistical field model TK03.GAD of [18] at $0^{\circ}$ (a), $30^{\circ}$ (b) and $60^{\circ} \mathrm{N}(\mathrm{c})$. These are plotted as equal area projections with the expected GAD direction at the center of the plot. Solid (open) symbols are lower (upper) hemisphere, respectively. (d) Variations of elongation and inclination as a function of (paleo)latitude from realizations of the TK03.GAD statistical model for the geomagnetic field [18]. (e) Variation of elongation as a function of inclination from Fig. 3d. 
ratio of the intermediate to minimum eigenvalues $\left(\tau_{2} /\right.$ $\tau_{3}$ ) of the directional covariance matrix of [31] (This $E$ is somewhat different than that of [29] who uses $k_{1}$ and $k_{2}$ of the Bingham distribution [32]). We plot the variation of the elongation and GAD inclination as a function of latitude in Fig. 2d. Because both elongation and inclination vary as a function of latitude (elongation decreasing and inclination increasing with increasing latitude), there is a unique value of elongation with respect to inclination as shown in Fig. 2e. According to the elongation/inclination method of [18], a given mean inclination can be used to derive paleolatitude if the corresponding elongation agrees with that expected from TK03.GAD as well.

Tauxe and Kent [18] proposed using the statistical geomagnetic field model TK03.GAD to characterize the directional dispersion expected from a GGP generated GAD field. They pointed out that if paleomagnetic directions have been affected by, say, inclination error, then the directional dispersion can be predicted. Inclination error has the well-known inclination error formula $\tan I_{\mathrm{o}}=f \tan I_{f}$ [33] where $I_{\mathrm{o}}$ is the observed inclination, $I_{f}$ is that of the applied field and $f$ a "flattening factor" ranging from 1 (no flattening) to 0 (total flattening). Laboratory experiments have found $f$ values ranging from $\sim 0.4[33]$ to 0.55 [34].

A given directional data set (declination $D$ and inclination I) can be "unflattened" by the formula tan $I^{* *}=(1 / f)$ tan $I_{\mathrm{o}}$ where $I^{* *}$ is the estimated original field direction assuming a value of $f$. The mean inclination $I^{* *}$ of the unflattened data $D, I^{* *}$ and the elongation $E$ can be evaluated as a function of $f$ to find the "optimum" value of $f$ that simultaneously gives values for $I^{* *}$ and $E$ that are consistent with TK03.GAD. It should be noted that this technique will only work if there are enough observations to adequately represent the statistical distribution of the geomagnetic field.

\section{Testing the $E / I$ method on the paleomagnetic directions of Spain}

To test the $E / I$ method, we require a region that has not experienced major differential translation with respect to the continent to which it belongs, leaving inclination error as the most likely explana- tion for the inclination anomaly. To this end, we have selected the Miocene sediments of the Calatayud basin of Spain $\left(\lambda=41.5^{\circ} ; \phi=358.5^{\circ}\right)$ for this study (Fig. 1) because of the wealth of good quality paleomagnetic sites of middle-late Miocene age (17-11 Ma) that had originally been sampled for magnetostratigraphic purposes $[35,36]$. Spain has been attached to Europe since the formation of the Pyrenees in the early Tertiary, so the reference poles for the European plate can be used to predict directions expected from a GAD field at any place on any linked location. An updated compilation of paleopoles for the European and African plates ([37], hereafter BC02) shows very good agreement ( $\sim 97 \%$ ) with the GAD model.

Using the middle Miocene (20-10 Ma) mean paleopoles for Europe $(\lambda=81.4-85 ; \phi=149.9-155.7)$ of $\mathrm{BC} 02$ predicts a mean expected inclination $\langle I\rangle$ of 53.3$56.3^{\circ}$ for the Calatayud basin during deposition of the sediments, implying a paleolatitude of $33.9-36.9^{\circ} \mathrm{N}$. The mean direction of the 648 sites is, however, $D=1.2^{\circ}, I=44.0^{\circ}$ (Fig. 1). If this direction was produced by a GAD field, the paleolatitude would be $25.8^{\circ} \mathrm{N}$, implying an unrealistic southward offset of more than $1000 \mathrm{~km}$ from Europe. Such a geologically untenable offset strongly suggests that the sediments of the Calatayud basin have been affected by inclination error. The distribution of the directions is indeed only slightly elongated $\mathrm{N}-\mathrm{S}$, while at the predicted paleolatitude, we would expect a significant elongation of 1.6 (Fig. 1d).

We apply the $E / I$ method by systematically unflattening the Spanish directions with values of $f$ ranging from unity to 0.3 (Fig. 3a). At each unflattening step, we evaluate the mean inclination and elongation. We also take 1000 bootstrapped samples of the data and repeat the analysis. Examples of bootstrapped curves are shown as lighter lines in Fig. 3a while the original data are shown as the heavy line with tick marks indicating the azimuth of the elongation direction. In Fig. 3a, we also plot elongation versus inclination expected from TK03.GAD (dashed line). The crossing point of a given elongation/inclination versus $f$ curve (e.g., hatched) with the model curve (dashed) gives a unique $E / I$ pair consistent with the field model. The elongation/inclination pair from the original data consistent with TK03.GAD is achieved with a flattening value $f$ of 0.68 . In Fig. 3b, we plot a histogram of all 


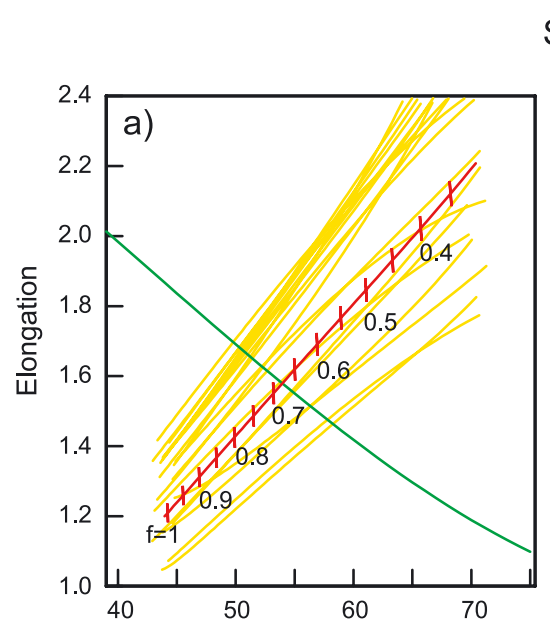

Spain
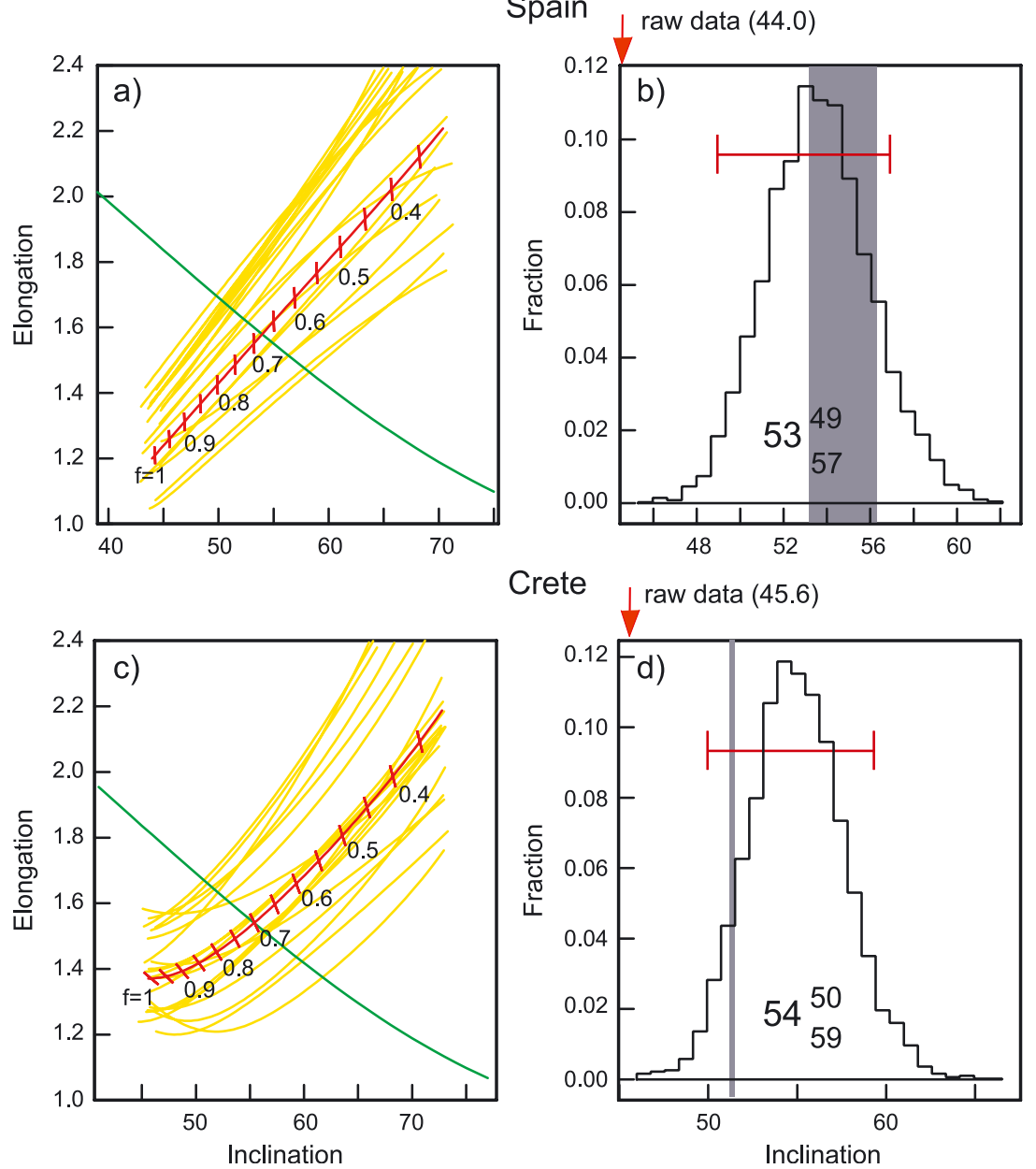

Fig. 3. (a) Plot of elongation versus inclination for the TK03.GAD model (dashed line) and for the Spanish data of the Calatayud basin (barbed line) for different values of $f$. The barbs indicate the direction of elongation with horizontal being $\mathrm{E}-\mathrm{W}$ and vertical being $\mathrm{N}-\mathrm{S}$. Also shown are results from 20 bootstrapped data sets. The crossing points represent the inclination/elongation pair most consistent with the TK03.GAD model. (b) Histogram of crossing points from 5000 bootstrapped data sets. The most frequent inclination $\left(53^{\circ}\right)$ is in good agreement with the predicted middle Miocene inclinations $\left(53.3-56.3^{\circ}\right.$ ) for the region from the BC02 European apparent polar wander path (gray shading). The $95 \%$ confidence bounds on this estimate are $49-57^{\circ}$ (red line). Arrow on top indicates the mean inclination $\left(44^{\circ}\right.$ ) of the raw data paleomagnetic displayed in Fig. 1. (c and d) Same as in (a) and (b) but for Crete.

inclinations derived from the bootstrapped crossing points as well as the $95 \%$ confidence bounds (49$57^{\circ}$ ). The mode is $53^{\circ}$, corresponding to a paleolatitude of $33.6^{\circ}$. This direction is in good agreement with the expected inclination for the Calatyud basin derived from $\mathrm{BC} 02$ (Fig. 3b). It shows that the anomalously shallow inclinations in the sediments of the Calatuyud basin are indeed likely to be caused by inclination error but that application of the $E / I$ method yields the expected paleolatitude.

\section{Applying the $E / I$ method to the paleomagnetic directions of Crete}

The Aegean region represents a piece of continental lithosphere undergoing widespread extension in the general setting of Africa-Europe convergence. Seismic tomography has shown that the African plate subducts to a depth of several hundreds of kilometers at the longitude of Crete [38]. Rollback of the Hellenic subduction zone initiated extension in 
the Aegean area and generated a southward translation of Crete (e.g., [20]). Geodetic observations indicate that this southward movement of Crete continues even today [23]. The total amount of extension in the Aegean area is estimated at about $300 \mathrm{~km}$ (e.g., [21]).

Numerous paleomagnetic studies have been performed on the late Miocene sediments from Crete, especially focussing on vertical axis rotation (e.g., $[17,39])$ and on magnetostratigraphic dating (e.g., [40-42]). The central part of Crete is presently located at $35.2^{\circ} \mathrm{N}$ and $25^{\circ} \mathrm{E}$. This has a corresponding GAD inclination of $54.8^{\circ}$. The main conclusion derived from the declination data was that Crete as a whole did not experience any significant rotation since Tortonian times [17], although many sites showed counterclockwise rotations related to local fault-bounded blocks [39]. The mean direction of the 20 sites $(9$ reversed and 11 normal) of [17] is $D=358.9^{\circ}, I=45.7^{\circ}$. The magnetostratigraphic data set is much larger, having 686 sites of good quality directions [41-43]. The directions have been adjusted for their local block rotation (see [39]) and are shown in Fig. 1. They have a mean inclination of $45.6^{\circ}$, in agreement with [17].

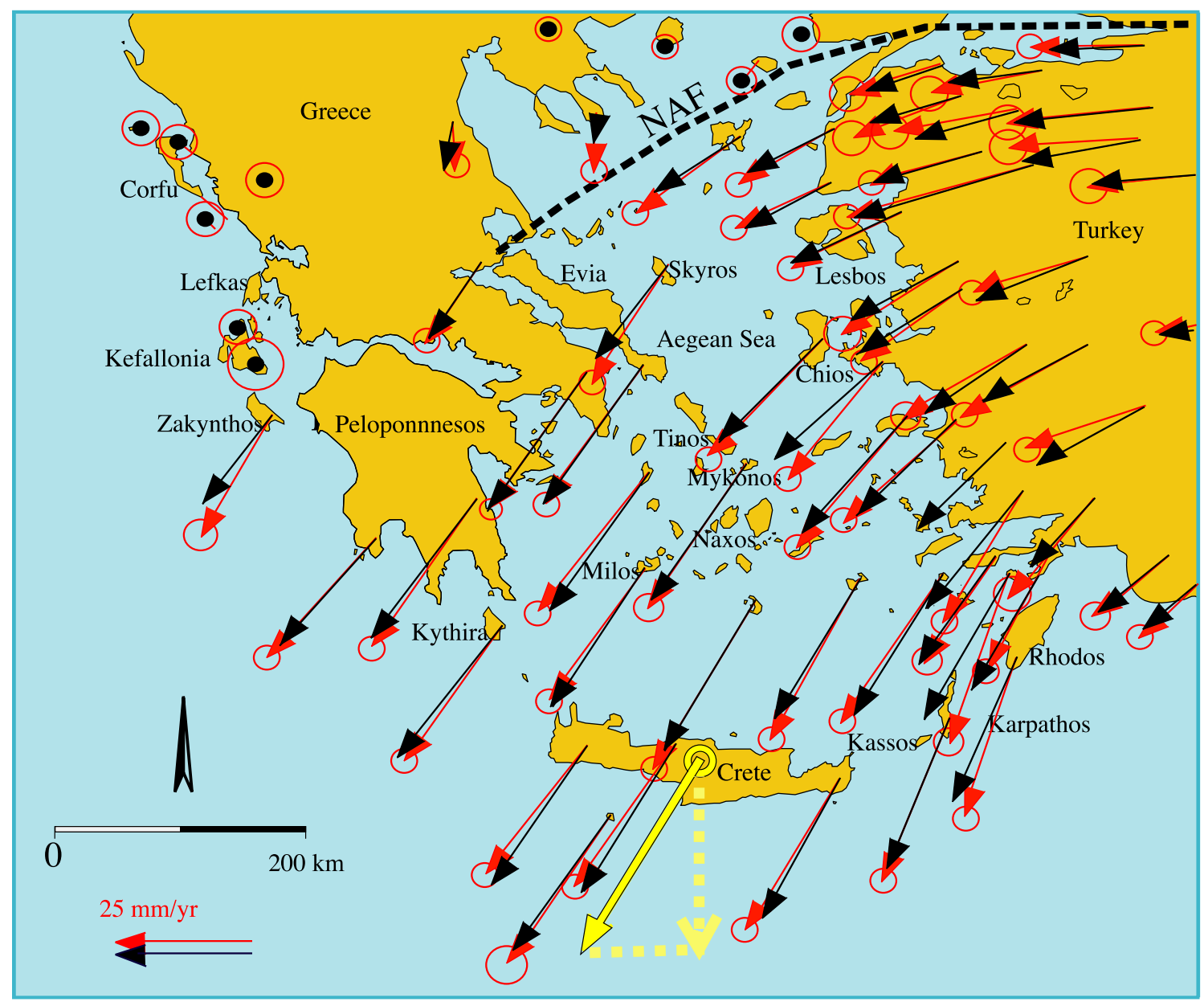

Fig. 4. Map of the Aegean region showing the geodynamic model ([22], black arrows) and GPS ([23], red arrows) data. The 95\% confidence ellipses of the GPS data are shown as circles. The yellow arrow attached to crete is the displacement vector of Crete for the last $7.5 \mathrm{Myr}$. The southward component (dashed arrow) is inferred from paleomagnetic data corrected with the $E / I$ method, and the vector is forced to align with the GPS constrained motion. 
Using the $\mathrm{BC} 02$ mean paleopoles (10-5 Ma) for Europe $(\lambda=85-86.3 ; \phi=155.7-172.0)$, the expected late Miocene mean inclination $\langle I\rangle$ is $51.2-51.4^{\circ}$ suggesting a paleolatitude of Crete of $31.9-32.1^{\circ} \mathrm{N}$. The magnetic inclinations for Crete are quite shallow, implying that Crete was at a paleolatitude of $27^{\circ} \mathrm{N}$ during this period, i.e., somewhere in the Sahara. However, the elongation of the directions $E=1.4$ is not in agreement with the expected $\mathrm{N}-\mathrm{S}$ elongation of 1.9 for this inclination (Figs. $2 \mathrm{~d}$ and $3 \mathrm{c}$ ). It is thus possible that the anomalously shallow Cretan data are caused by inclination error.

The E/I method suggests that the relationship between elongation and latitude can be used to find the paleolatitude of Crete for which the directional data are in agreement with the TK03.GAD model. We show the results in Fig. 3c. These show that the most consistent $E / I$ pair is obtained when a flattening parameter $f$ of 0.7 is used to transform the directions to a mean inclination $I^{* *}=54^{\circ}$. This corresponds to a paleolatitude of $34.5^{\circ} \mathrm{N}$ (Fig. 3c,d). The location of Crete in the late Miocene expected from the $E / I$ method is therefore $2.5^{\circ}$ more to the north than its position would be if Crete were solidly attached to Europe. These results are consistent with the suggestion that Crete moved about $275 \mathrm{~km}$ southward with respect to Europe since the late Miocene, and imply an average southward displacement rate of $37 \mathrm{~mm} / \mathrm{yr}$ for the last 7.5 Myr.

The $E / I$ predicted paleolatitude is in agreement with the geodynamical models of the east Mediterranean, which suggests an extension of approximately $300 \mathrm{~km}$ for the Aegean and a Miocene position of Crete close to the present day Peloponnesos. It was earlier argued that strain patterns and rates in the Aegean domain have not significantly changed during the last 20-30 Myr, with only a stronger localization of extension due to the formation of the North Anatolian Fault in the Pliocene [21]. The present velocity field of the Aegean region is nowadays well constrained (Fig. 4) as the density of global positioning system (GPS) coverage has improved (e.g., [23]). Geological models that explain the deformation in the Aegean are now subject to tests using these GPS data (e.g., [21,22]). We plot the displacement vector for Crete, as determined by the corrected paleomagnetic data, in the same figure for comparison with model data [22] and GPS data [23] (Fig. 4). It is very interesting to note that our paleomagnetic displacement vector shows a good correspondence with the present-day velocity field as determined from GPS measurements. For the first time, it will thus be possible to obtain a detailed paleogeographic picture of the geological past, based on sedimentary paleomagnetic data, from areas for which the plate tectonic evolution could so far only be reconstructed by geological models. Our results indicate that anomalously shallow inclinations of sediments in the Hellenic arc are significantly influenced by inclination error but that paleomagnetic inclinations, after application of the E/I method, can nonetheless be used for tectonic reconstructions, provided that a large data set is available.

\section{The east Mediterranean inclination anomaly}

Paleomagnetic studies of Cenozoic rock units from especially the eastern Mediterranean have consistently documented mean inclinations that are systematically very shallow (by about $10^{\circ}$ ) than expected on the basis of a GAD field. This was already recognised by the first paleomagnetic studies on sediments from the Aegean arc and interpreted as most likely caused by compaction of the sediment or by inclination error [17]. Inclinations found in Tertiary igneous rocks, where compaction is irrelevant, appeared to be very shallow as well [44-46]. This led to an alternative suggestion, implying that a large departure from the GAD hypothesis had occurred during the Eocene [13]. On the other hand, anomalously shallow inclinations have been consistently reported from Eo-Oligocene to Mio-Pliocene rocks in the eastern Mediterranean. Rocks and apparent polar wander paths from other continents, however, do not show corresponding anomalies (apart from several sites in China [12]), which seems to rule out the possibility of an offcentered dipole or a significant nondipole component in the magnetic field. As a result, the shallow inclinations have been interpreted as being caused by a significant northward translation of the Aegean area or to unrecognised tilt of the strata $[7,8]$. Significant northward displacement is, however, geologically unrealistic, particularly for Neogene units, because it places the Aegean region south of the northern African margin. 
Our results from the Miocene sediments of Crete show that, when inclination error is taken into account and the resulting mean inclination is matched with an expected value for elongation from a statistical field model, the shallow bias in the paleomagnetic directions is completely compensated. The corrected data suggest that Crete was located about $275 \mathrm{~km}$ more to the north in the late Miocene and that, in fact, southward displacement must have taken place. We believe that the east Mediterranean inclination problem is best explained by inclination error, which causes a shallow bias in the paleomagnetic directions. Nevertheless, it has often been argued that inclination flattening cannot explain the anomalously shallow inclinations observed in volcanic rocks $[8,45]$. Consequently, the tectonic explanation, including accommodation of $\sim 500 \mathrm{~km}$ northward displacement with respect to Europe was recently put forward again by Beck et al. [9] on the basis of paleomagnetic results from igneous rocks of Lesbos.

Beck et al. [9] base their arguments on two premises. Firstly, they argue that 17 of 18 studies from igneous rocks of the Aegean region yield mean inclinations that are shallower than expected from apparent polar wander curves of Europe. They collected an additional 44 sites from 16-22 Ma volcanic rocks from Lesbos in the northeastern Aegean and performed modern paleomagnetic laboratory analyses, producing a mean inclination that, while consistent with a GAD field within, the uncertainty $\left(5.9^{\circ} \pm 6.1^{\circ}\right)$ is on the shallow side. They adjusted the directions by the estimated attitudes of the dominantly rhyolitic and andesitic lava flows (which can have initial dips of some $30^{\circ}$ ) as well as some dykes (whose original orientations are difficult to constrain). Some of the "bedding attitudes" are those of associated sedimentary units but most are not. We address these issues using Monte Carlo simulations in Fig. 5.

We investigate the possible cause of shallow bias in small data sets by drawing a set of 1000 geomagnetic field vectors from TK03.GAD evaluated at a latitude of $35^{\circ} \mathrm{N}$ (shown in the inset to Fig. 5a). The vector mean of these yields the inclination expected from a GAD field of $54.5^{\circ}$. From this set of directions, we randomly draw $N$ "sites" and calculate a Fisher mean (i.e., assuming unit length for all vectors). We repeat this procedure 1000 times. Representative results are shown as histograms of average inclination for each size of $N$. The proportion of "studies" with shallow bias increases with increasing number of sampling sites. A total of $87 \%$ of all studies with $N=20$ sites have average inclinations that are a)

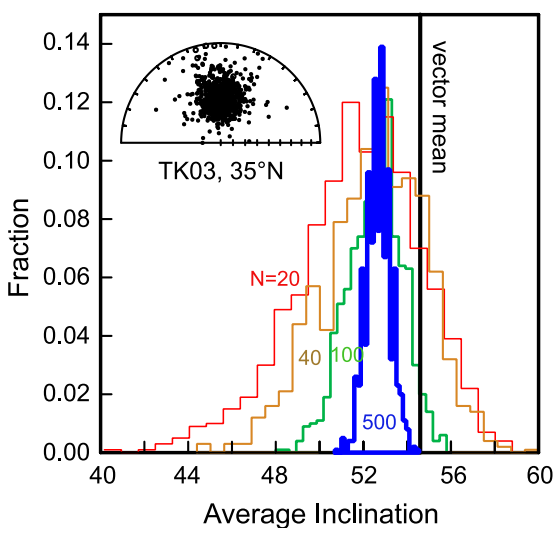

b)

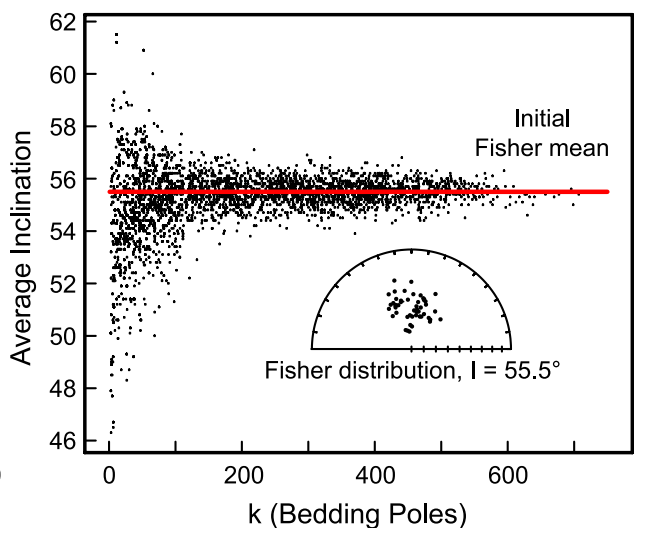

Fig. 5. (a) Fisher mean inclinations from data sets with varying number of sampling sites. Including the intensity data, taking 1000 directions from TK03.GAD evaluated at $35^{\circ}$ (shown in the inset) gives the correct GAD inclination of $55.5^{\circ}$. Neglecting intensity yields a slight shallow bias of a few degrees. Histograms are results from 1000 simulations each drawing $N$ directions from TK03.GAD and calculating the mean Fisher distribution. There is a very strong bias in undersampled data sets. (b) Simulations of the effect of random tilt on paleomagnetic directions shown in insert. Directions are "corrected" assuming poles to bed were drawn from a Fisher distribution with vertical mean and $k$ ranging from 1 to 700 . Dots are means of "corrected" data sets. Heavy solid line is initial Fisher mean of $55.5^{\circ}$. There is a shallow bias to data sets having incorrect bedding attitudes. 
below the GAD expectation, while $100 \%$ of all studies with $N=500$ did. However, the magnitude of the bias is certainly largest with studies with fewer sites and can be more than $6^{\circ}$ very shallow with the number of sites typical of the studies cited by Beck et al. [9] (see Fig. 5a).

While there is a likelihood of substantial shallow bias from under sampling the geomagnetic field, there is also a small bias that comes from the neglect of intensity as pointed out by Creer [47]. Tauxe and Kent [18] show that this results from the mapping of circularly symmetric VGPs to elliptical distributions of directions with the ellipse being offset from the mean toward shallow directions at intermediate inclinations. Neglect of intensity enhances the bias because the most deviant directions are virtually always associated with low intensities, particularly when estimated using Fisher statistics [48]. The bias is less when using the principal component of the directional covariance matrix (see [49]). The "Creer" effect is likely to be more important in igneous units that record instantaneous field states. Sedimentary samples average (vectorially) over at least the width of the sample, from hundreds to a thousand years depending on sedimentation rate. The extreme directions are likely to be short lived; hence, they will tend to be missed, reducing the shallow bias.

Beck et al. [9] report data from Lesbos with a mean inclination of $51.7^{\circ}\left(\alpha_{95}=6.89\right)$, which is consistent with the inclination expected for that location by $\operatorname{BC} 02\left(53.9^{\circ}, \alpha_{95}=4.5\right)$. [Beck et al. used an earlier version of the European pole paths to calculate the expected inclination, which was a degree or so steeper than that predicted by BC02.] After adjusting for estimated bedding attitudes, the mean inclination of the Lesbos data was shallower by several degrees and Beck et al. [9] argue that the difference is significant.

An additional problem with the Lesbos data concerns the effect of inappropriate tilt corrections. In the Beck et al. study, scatter increased slightly (although not significantly) and the average inclination decreased after rotation by the estimated bedding attitude. The bedding poles are essentially vertical, with a Fisher [48] concentration parameter of 34. Perhaps surprisingly, it turns out that the application of inappropriate tilt "corrections" results in an increased likelihood of shallow bias. We illustrate this in Fig. 5 b. We start with a Fisher distributed set of 50 directions shown in the inset to Fig. 5b. These have a mean direction of $D=0.4, I=55.5$ and a Fisher concentration parameter $k$ of 31 [48]. We draw 50 "bedding poles" from a Fisher distribution with concentration parameters (estimated by Fisher's $k$ ) ranging from 1 to 700 about a vertical mean. These are used to adjust the directions in the starting data set, after which we calculate a new mean direction. The average inclination for each trial is plotted as a dot in Fig. $5 \mathrm{~b}$ against the value for $k$ in each set of bedding poles. As the concentration of the bedding poles decreases, the resulting average inclination is increasingly inaccurate (as expected), but there is a strong bias towards being very shallow rather than very steep. Hence, application of inaccurate structural tilt corrections leads to a shallow bias in inclinations. Therefore, it is perhaps not surprising that the tilt adjusted mean value of Beck et al. [9] is shallower than the unadjusted mean, bolstering their argument for anomalous geomagnetic fields. We find no support for such an interpretation.

\section{Conclusions}

The middle to late Miocene continental sediments of the Calatayud basin in northeastern Spain and the late Miocene marine marls from the island of Crete both exhibit anomalously shallow inclinations in the paleomagnetic directions. We applied a new method, the elongation/inclination method of Tauxe and Kent [18], which relies on a statistical field model (TK03.GAD) to diagnose and correct for possible directional bias resulting from inclination error in the unusually large paleomagnetic data set (between 600 and 700 sites). The principal directions of the corrected data from the Calatayud basin appear to be in good agreement with the expected middle Miocene position of Spain, indicating that the original shallow bias in the magnetic directions was indeed caused by inclination error. The mean directions of Crete, after correction for inclination error, indicate that, in the late Miocene, it occupied a position about $275 \mathrm{~km}$ more to the north than its predicted location, assuming Crete has been solidly attached to Europe. Southward translation of Crete is also in agreement with the geological and geodetic data from the Aegean region; furthermore, the average southward displacement rate 
of $37 \mathrm{~mm} / \mathrm{yr}$ matches well with the GPS velocity vectors for present-day deformation in the Aegean Sea. We demonstrate that mean inclinations from paleomagnetic studies with a limited number of sampling sites are likely to be biased very shallow and that application of inappropriate structural corrections also results in a shallow bias. These results illuminate the cause of shallow bias in studies of igneous units from the Aegean region.

We believe that the largely controversial and, so far, unexplained eastern Mediterranean inclination anomaly is fully accounted for by inclination error in the paleomagnetic directions. Far-reaching hypotheses, such as major northward translation of the Aegean area with respect to Europe or the presence of large nondipole components in the Earth magnetic field, are thus not necessary to explain the shallow bias in the Mediterranean paleomagnetic directions.

\section{Acknowledgements}

We thank Cor Langereis, Hayfaa Abdul Aziz and Charon Duermeijer for providing their data, and Bob Butler, Ken Kodama and Rob Van der Voo for their constructive reviews. Special thanks go to Hans Laeven for sending the Krijgsman family to San Diego. We also acknowledge stimulating conversations with Dennis Kent, Geoff King, Vincent Courtillot, Guillaume Dupont-Nivet, Cathy Constable and Catherine Johnson. We acknowledge support by the Netherlands Geosciences Foundation (ALW) with financial aid from the Netherlands Organization for Scientific Research (NWO). This work was carried out under the program of the Vening Meinesz Research School of Geodynamics (VMSG). We also acknowledge support of the National Science Foundation (NSF) grant EAR0003395 to LT. [SK]

\section{References}

[1] D.V. Kent, M.A. Smethurst, Shallow bias of paleomagnetic inclinations in the Paleozoic and Precambrian, Earth Planet. Sci. Lett. 160 (1998) 391-402.

[2] J. Cogné, N. Halim, Y. Chen, V. Courtillot, Resolving the problem of shallow magnetizations of Tertiary age in Asia: insights from paleomagnetic data from the Qiangtang, Kun- lun, and Qaidam blocks (Tibet, China), and a new hypothesis, J. Geophys. Res. 104 (1999) 17715-17734.

[3] D.E. Champion, D.G. Howell, C.S. Gromme, Paleomagnetic and geologic data indicating $2500 \mathrm{~km}$ of northward displacement for the Salinian and related terranes, California, J. Geophys. Res. 89 (1984) 7736-7752.

[4] J.T. Hagstrum, M. McWilliams, D.G. Howell, S. Grommé, Mesozoic paleomagnetism and northward translation of the Baja California Peninsula, GSA Bull. 96 (1985) 1077-1090.

[5] K.J. Whidden, S.P. Lund, D. Champion, D.J. Bottjer, D.G. Howell, Paleomagnetic evidence that the central block of Salinia (California) is not a far-traveled terrane, Tectonics 17 (1997) 329-343.

[6] P.D. Ward, J.M. Hurtado, J.L. Kirschvink, K.L. Verosub, Measurements of the cretaceous paleolatitude of Vancouver Island: consistent with the Baja-British Columbia hypothesis, Science 277 (1997) 1642-1645.

[7] C. Kissel, C. Laj, The Tertiary geodynamical evolution of the Aegean arc: a paleomagnetic reconstruction, Tectonophysics 146 (1988) 183-201.

[8] M. Beck, E. Schermer, Aegean paleomagnetic inclination anomalies. Is there a tectonic explanation? Tectonophysics 231 (1994) 281-292.

[9] M.E. Beck, R.F. Burmester, D.P. Kondopoulou, A. Atzemoglou, The palaeomagnetism of Lesbos, NE Aegean, and the eastern Mediterranean inclination anomaly, Geophys. J. Int. 145 (2001) 233-245.

[10] S. Gilder, Y. Chen, S. Sen, Oligo-Miocene magnetostratigraphy and rock magnetism of the Xishuigou section, Subei (Gansu Province, western China) and implications for shallow inclinations in central Asia, J. Geophys. Res. 106 (2001) 30505-30521.

[11] G. Gastil, Is there a Oaxaca-California megashear? Conflict between paleomagnetic data and other elements of geology, Geology 19 (1991) 502-505.

[12] J. Si, R. Van der Voo, Too-low magnetic inclinations in central Asia: an indication of a long term Tertiary non-dipole field? Terra Nova 13 (2001) 471-478.

[13] M. Westphal, Did a large departure from the geocentric axial dipole hypothesis occur during the Eocene? Evidence from the magnetic polar wander path of Eurasia, Earth Planet. Sci. Lett. 117 (1993) 15-28.

[14] R.F. Butler, W.R. Dickinson, G.E. Gehrels, Paleomagnetism of coastal California and Baja California: alternatives to largescale northward transport, Tectonics 10 (1991) 561-576.

[15] G. Dupont-Nivet, Z. Guo, R. Butler, C. Jia, Discordant paleomagnetic direction in Miocene rocks from the central Tarim basin: evidence for local deformation and inclination shallowing, Earth Planet. Sci. Lett. 199 (2002) 473-482.

[16] K. Kodama, J.M. Davi, A compaction correction for the paleomagnetism of the cretaceous pigeon point formation of California, Tectonics 14 (1995) 1153-1164.

[17] J.-P. Valente, C. Laj, D. Sorel, S. Roy, J.-P. Valet, Paleomagnetic results from Mio-Pliocene marine sedimentary series in Crete, Earth Planet. Sci. Lett. 57 (1982) 159-172.

[18] L. Tauxe, D.V. Kent, A new statistical model for the geomagnetic field and the detection of shallow bias in paleomagnetic 
inclinations: was the ancient magnetic field dipolar? in: J.E.T. Kent, D.V. Kent, W. Lowrie, J. Meert (Eds.), Timescales of the Internal Geomagnetic Field, in press.

[19] L. Lonergan, N. White, Origin of the Betic-Rif mountain belt, Tectonics 16 (1997) 504-522.

[20] J. Angelier, N. Lybéris, X. Le Pichon, E. Barrier, P. Huchon, The tectonic development of the Hellenic arc and the Sea of Crete: a synthesis, Tectonophysics 86 (1982) 159-196.

[21] L. Jolivet, A comparison of geodetic and finite strain pattern in the Aegean, geodynamic implications, Earth Planet. Sci. Lett. 187 (2001) 95-104.

[22] R. Armijo, F. Flerit, G. King, B. Meyer, Linear elastic fracture mechanics explains the past and present evolution of the Aegean, Earth Planet. Sci. Lett. 217 (2003) 85-95.

[23] S. McClusky, S. Balassanian, A. Barka, C. Demir, S. Ergintav, I. Georgiev, O. Gurkan, M. Hamburger, K. Hurst, H.G. Kahle, K. Kastens, G. Kekelidze, R. King, V. Kotzer, O. Lenk, S. Mahmoud, A. Mishin, M. Nadariya, A. Ouzounis, D. Paradissis, Y. Peter, M. Prelepin, R. Reilinger, I. Sanli, H. Seeger, A. Tealeb, M.N. Toksöz, G. Veis, Global positioning system constraints on plate kinematics and dynamics in the eastern Mediterranean and Caucasus, J. Geophys. Res. 105 (2000) $5695-5719$.

[24] C.G. Constable, R.L. Parker, Statistics of the geomagnetic secular variation for the past 5 m.y., J. Geophys. Res. 93 (1988) 11569-11581.

[25] K.A. Hoffman, A method for the display and analysis of transitional paleomagnetic data, J. Geophys. Res. 89 (1984) $6285-6292$.

[26] C. Baag, C.E. Helsley, Shape analysis of paleosecular variation data, J. Geophys. Res. 79 (1974) 4923-4932.

[27] M. Kono, Distributions of paleomagnetic directions and poles, Phys. Earth Planet. Inter. 103 (1997) 313-327.

[28] H. Tanaka, Circular asymmetry of the paleomagnetic directions observed at low latitude volcanic sites, Earth Planets Space 51 (1999) 1279-1286.

[29] M.E. Beck, On the shape of paleomagnetic data sets, J. Geophys. Res. 104 (1999) 25427-25441.

[30] L. Tauxe, Paleomagnetic Principles and Practice, Kluwer Academic Publishing, Dordrecht, 1998.

[31] G.S. Watson, More significance tests on the sphere, Biometrika 47 (1960) 91-97.

[32] C. Bingham, An antipodally symmetric distribution on the sphere, Ann. Statist. 2 (1974) 1201-1225.

[33] R.F. King, Remanent magnetism of artificially deposited sediments, Mon. Not. R. Astron. Soc., Geophys. Suppl. 7 (1955) $115-134$

[34] L. Tauxe, D.V. Kent, Properties of a detrital remanence carried by haematite from study of modern river deposits and laboratory redeposition sediments, Geophys. J. R. Astron. Soc. 76 (3) (1984) 543-561.
[35] W. Krijgsman, C.G. Langereis, R. Daams, A.J.V.D. Meulen, Magnetostratigraphic dating of the middle Miocene climate change in the continental deposits of the Aragonian type area in the Calatayud-Teruel basin (central Spain), Earth Planet. Sci. Lett. 128 (1994) 513-526.

[36] H. Abdul Aziz, F.J. Hilgen, W. Krijgsman, E. Sanz-Rubio, J.P. Calvo, Astronomical forcing of sedimentary cycles in the Miocene continental Calatayud basin (NE Spain), Earth Planet. Sci. Lett. 177 (2000) 9-22.

[37] J. Besse, V. Courtillot, Apparent and true polar wander and the geometry of the geomagnetic field over the last $200 \mathrm{Myr}$, J. Geophys. Res. 107 (2002) doi:10.1029/2000JB000,050.

[38] W. Spakman, M.J.R. Wortel, N.J. Vlaar, The Hellenic subduction zone: a tomographic image and its geodynamic implications, Geophys. Res. Lett. 15 (1988) 60-63.

[39] C.E. Duermeijer, W. Krijgsman, C.G. Langereis, J.H. Ten Veen, Post-early Messinian counterclockwise rotations on Crete: implications for late Miocene to Recent kinematics of the southern Hellenic arc, Tectonophysics 298 (1998) $177-189$.

[40] C.G. Langereis, W.J. Zachariasse, J.D.A. Zijderveld, Late Miocene magnetobiostratigraphy of Crete, Mar. Micropaleontol. 8 (1984) 261-281.

[41] W. Krijgsman, F.J. Hilgen, C.G. Langereis, W.J. Zachariasse, The age of the Tortonian/Messinian boundary, Earth Planet. Sci. Lett. 121 (1994) 533-547.

[42] W. Krijgsman, F.J. Hilgen, C.G. Langereis, A. Santarelli, W.J. Zachariasse, Late Miocene magnetostratigraphy, biostratigraphy and cyclostratigraphy in the Mediterranean, Earth Planet. Sci. Lett. 136 (1995) 475-494.

[43] C.G. Langereis, Late Miocene magnetostratigraphy in the Mediterranean, PhD thesis, Rijksuniversiteit Utrecht, 1984.

[44] M. Westphal, M. Bazhenov, J. Lauer, M. Pechersky, J. Sibuet, Paleomagnetic implications of the evolution of the Tethys belt from the Atlantic Ocean to the Pamirs since the Triassic, Tectonophysics 123 (1986) 37-82.

[45] C. Kissel, C. Laj, A. Sengor, A. Poisson, Paleomagnetic evidence for rotation in opposite senses of adjacent blocks in northeastern Aegea and western Anatolia, Geophys. Res. Lett. 14 (1987) 907-910.

[46] E. Aidona, D. Kondopoulou, A. Georgakopoulos, Paleomagnetic and rock magnetic properties of sediment cores from Chalkidiki, Greece, Phys. Chem. Earth 26 (2001) 879-884.

[47] K.M. Creer, Computer analysis of geomagnetic palaeosecular variations, Nature 304 (1983) 695-699.

[48] R.A. Fisher, Dispersion on a sphere, Proc. R. Soc. London, A 217 (1953) 295-305.

[49] L. Tauxe, N. Kylstra, C. Constable, Bootstrap statistics for paleomagnetic data, J. Geophys. Res. 96 (1991) 11723-11740. 